\title{
TRATAMENTOS EXPERIMENTAIS NA PANDEMIA DA COVID-19 - TERMO DE CONSENTIMENTO LIVRE E ESCLARECIDO E RESPONSABILIDADE CIVIL
}

\author{
EXPERIMENTAL TREATMENTS AND PANDEMIC \\ COVID-19 - INFORMED CONSENT TERM AND \\ CIVIL RESPONSIBILITY
}

\begin{abstract}
Daniela Braga Paiano
Professora do Departamento de Direito Privado e do Programa de Mestrado e Doutorado em Direito Negocial na Universidade Estadual de Londrina- UEL. Doutora em Direito Civil pela USP. ORCID: https://orcid.org/0000-0002-8926-6555

Alessandra Cristina Furlan

Professora da Universidade Estadual Norte do Paraná - UENP. Doutora em Direito Civil pela USP. ORCID: https://orcid.org/0000-0002-4533-3103
\end{abstract}

\begin{abstract}
Resumo: 0 presente artigo aborda o tratamento experimental, diferenciando-o de experiência terapêutica, ressaltando a importância das pesquisas tanto para o próprio indivíduo, quanto para a humanidade. Analisa a licitude dos tratamentos experimentais amparada em diversos documentos do Conselho Federal de Medicina (CFM) - em especial o Parecer no 4/2020, Código de Ética Médica, Código Civil, Código Penal e Constituição Federal. Aborda aspectos do termo de consentimento livre e esclarecido (TCLE) e finaliza com a análise da responsabilidade civil médica e hospitalar no cenário experimental. A pesquisa tem cunho teórico e crítico, desenvolvida à luz do método científico lógico-dedutivo, utilizando a pesquisa bibliográfica, legislativa e jurisprudencial como procedimento metodológico.
\end{abstract}

Palavras-chave: Tratamentos experimentais. Licitude. TCLE. Responsabilidade civil.

Abstract: This article will analyze experimental treatment, making difference from therapeutic experience, emphasizing the importance of research both for individuals and for mankind. It analyzes the legality of experimental treatments supported by several resolutions of the Federal Council of Medicine (CFM) - in particular technical advice no 4/2020, Code of Medical Ethics, Civil Code, Penal Code and Federal Constitution. Finally, it processes aspects of the Informed Consent Form and concludes with the analysis of medical and hospital civil responsibility in the experimental scenario. The research has a theoretical and critical nature, developed in the light of the logical-deductive scientific method, using bibliographic, legislative and jurisprudential research as a methodological procedure.

Keywords: Experimental treatments. Legality. Informed consent form. Civil responsibility. 
Sumário: Introdução - 10 que são tratamentos experimentais? - 2 A licitude dos tratamentos experimentais $\mathbf{-} \mathbf{3} 0$ termo de consentimento livre e esclarecido (TCLE) do paciente/participante $\mathbf{- 4} \mathrm{Da}$ responsabilidade civil em experiência terapêutica - Conclusão

\section{Introdução}

A manutenção e a recuperação da saúde tornaram-se exigências da sociedade contemporânea, que procura viabilizar os meios para satisfazê-las. Destinada a atender a tais reclamos, a saúde encontra-se incorporada no texto da Constituição Federal como um bem público, direito de todos e dever do Estado (art. 196). Viver de forma saudável constitui um dos objetivos da humanidade e este desiderato somente pode ser alcançado pela evolução científica e pelo acesso a conhecimentos atualizados.

Assim sendo, os procedimentos inovadores na área médica, por envolverem um plexo de direitos fundamentais, como vida e integridade física, impõem avaliação prévia para somente depois serem disponibilizados ao uso geral. A validação abrange pesquisas em laboratórios, experimentos com animais e finalmente testes em seres humanos, seguindo padrões científicos, éticos e jurídicos, de forma a reduzir os riscos aos participantes, uma vez que os efeitos investigados são desconhecidos. Ou seja, as pesquisas levam tempo para garantir a segurança e a eficácia de um novo medicamento ou de uma terapêutica inédita.

No dia 11.3.2020, o mundo foi surpreendido com a declaração de pandemia feita pela Organização Mundial de Saúde (OMS). A vertiginosa disseminação do coronavírus (Sars-CoV-2) pelos cinco continentes levou os países a adotarem medidas drásticas para conter a propagação da Covid-19, diminuir o número de infectados, bem como evitar o colapso do sistema de saúde.

Sem dúvida, é o maior desafio do século na área da saúde: como se trata de doença nova, a única estratégia reconhecida para impedir a infecção é evitar a exposição ao vírus, sendo o isolamento social recomendado no mundo todo, com nefastas repercussões no setor econômico. Segundo o Ministério da Saúde, além das vacinas, não há outras evidências científicas sobre um tratamento preventivo ou curativo com $100 \%$ de eficácia.

A urgência da situação exige que pessoas infectadas sejam tratadas, mesmo que os efeitos das terapêuticas adotadas pelos profissionais de saúde não estejam completamente desvendados, o que eleva os riscos à saúde e à vida dos pacientes.

De tal maneira, o tema central do estudo diz respeito aos tratamentos experimentais em época de pandemia, em especial, neste trabalho, a pandemia da 
Covid-19. Para tanto, parte-se da distinção entre tratamento individual inovador, pesquisa terapêutica e tratamentos consolidados. Na sequência, analisa-se a licitude dos tratamentos experimentais, para, então, abordar a importância do termo de consentimento livre e esclarecido dos pacientes com Covid-19. Finaliza com a responsabilidade civil médica e hospitalar nas terapêuticas não consolidadas.

Adverte-se que a investigação sobre a reparação e compensação de danos no âmbito da pesquisa com seres humanos não será abordada no presente manuscrito, uma vez que conta com regras diferenciadas, abrangendo a responsabilidade civil do pesquisador, da instituição e do patrocinador envolvidos nas diferentes fases do experimento.

\section{0 que são tratamentos experimentais?}

A medicina, por sua própria natureza, vale-se de um componente experimental. Civilizações antepassadas tratavam as patologias com base no acerto e no erro, até que uma prática se tornasse aceita. Nesse sentido, é correto afirmar que a história da experimentação é tão antiga quanto à da medicina. ${ }^{1}$

Atualmente, a situação é bastante diversa, uma vez que os novos medicamentos, métodos diagnósticos e terapêuticos exigem testes rígidos antes da disponibilização geral. Ou seja, na metodologia da ciência biomédica experimental, a investigação tem início com a construção de hipóteses que são testadas em laboratórios, in vitro, em animais e, também, em seres humanos. ${ }^{2}$

0 estudo com participação humana para aprovação de novos fármacos, medicamentos, vacinas e testes diagnósticos apresenta quatro fases, com pequenos e grandes grupos de voluntários saudáveis ou acometidos de determinada enfermidade. Por sua vez, as pesquisas destinadas à validação de novas terapias em medicina envolvem uma etapa de clínica restrita (até 50 pessoas) e outra de clínica expandida (número suficiente de pessoas para demonstrar a eficácia e a segurança do procedimento). ${ }^{3}$

Antes de iniciado, o protocolo precisa ser aprovado por comitê de ética independente, de forma a respeitar a proteção dos participantes. O voluntário, após

1 VARGA, Andrew C. Problemas de bioética. Tradução de Guido Edgar Wenzel. São Leopoldo: Unisinos, 2001. p. 139.

2 PESSINI, Leocir; BARCHIFONTAINE, Christian de Paul de. Problemas atuais de bioética. 11. ed. São Paulo: Centro Universitário São Camilo, 2014. p. 239.

3 Sobre o assunto, confira: DADALTO, Luciana; ROYO, Mayara Medeiros; COSTA, Beatriz Silva. Bioética e integridade científica nas pesquisas clínicas sobre Covid-19. Revista Bioética, Brasília, v. 28, n. 4, p. 418 425, 2020. Disponível em: https://revistabioetica.cfm.org.br/index.php/revista_bioetica/issue/view/75. Acesso em: 2 maio 2020. 
receber as informações essenciais - em especial, quanto aos riscos e benefícios do experimento -, assina um termo de consentimento livre e esclarecido (TCLE), requisito essencial para que um paciente participe das provas.

A pesquisa com seres humanos voluntários representa uma exigência das autoridades sanitárias para que seja autorizada a utilização e comercialização de novos produtos farmacêuticos, sendo a maneira de comprovar as propriedades de uma molécula e o seu uso seguro e confiável para a disponibilização geral. ${ }^{4}$

Cumpre lembrar a importância das pesquisas clínicas com novos medicamentos envolvendo seres humanos, uma vez "que beneficia os enfermos, previne, atenua ou debela uma série de doenças, problemas físicos ou psíquicos, além de propiciar bem-estar à saúde". ${ }^{5}$ Os ensaios clínicos têm ganhado "maior socialização e notoriedade em razão de avanços biotecnológicos, do aumento da procura por novas curas, da busca por tratamentos experimentais, seja por medicamentos ainda em pesquisa, seja por aqueles ainda não aprovados no país". ${ }^{6}$

No tocante à Covid-19, desde o final de 2019, dezenas de medicamentos estão sendo pesquisados, muitos deles têm se mostrado promissores nos testes em laboratório e por meio de observação clínica, mas nenhum ainda foi aprovado em ensaios clínicos com desenho cientificamente adequado. Logo, não podem ser recomendados com garantia de segurança e eficácia ${ }^{7}$. Todavia, cabe ressaltar que, até o momento atual, vacinas foram autorizadas e estão sendo utilizadas na tentativa de combate ao coronavírus.

A Comissão Nacional de Ética em Pesquisa (Conep), responsável pela análise ética dos projetos de pesquisa envolvendo seres humanos no país, diante da pandemia e considerada a emergência para enfrentar a doença, criou ações voltadas a agilizar a análise dos protocolos. Instituiu-se um processo de tramitação especial e os protocolos de pesquisa sobre a Covid-19 devem ser encaminhados diretamente para apreciação da Conep, sendo dispensável a análise pelo CEP. ${ }^{8}$

4 DALLARI, Analluza Bolivar. Balizamento do contrato de pesquisa clínica por normas de aplicação imediata: estudo do regime jurídico brasileiro. Tese (Doutorado em Direito) - Faculdade de Direito, Universidade de São Paulo, São Paulo, 2019. p. 22.

5 PEREIRA, Paula M. F. de L. O regime jurídico da responsabilidade civil nos ensaios clínicos no ordenamento Iuso-brasileiro. In: BARBOSA, Heloísa Helena; LEAL, Lívia Teixeira; ALMEIDA, Vitor. Biodireito: tutela jurídica das dimensões da vida. Indaiatuba: Foco, 2021. p. 114.

6 PEREIRA, Paula M. F. de L. O regime jurídico da responsabilidade civil nos ensaios clínicos no ordenamento Iuso-brasileiro. In: BARBOSA, Heloísa Helena; LEAL, Lívia Teixeira; ALMEIDA, Vitor. Biodireito: tutela jurídica das dimensões da vida. Indaiatuba: Foco, 2021. p. 114.

7 BRASIL. Conselho Federal de Medicina. Processo-Consulta CFM no/2020. Parecer CFM no 4/2020. Relator: Cons. Mauro Luiz de Britto Ribeiro, 16 de abril de 2020. Disponível em: https://sistemas.cfm. org.br/normas/visualizar/pareceres/BR/2020/4. Acesso em: 2 maio 2021.

8 DADALTO, Luciana; ROYO, Mayara Medeiros; COSTA, Beatriz Silva. Bioética e integridade científica nas pesquisas clínicas sobre Covid-19. Revista Bioética, Brasília, v. 28, n. 4, p. 418-425, 2020. p. 421. Disponível em: https://revistabioetica.cfm.org.br/index.php/revista_bioetica/issue/view/75. Acesso em: 2 maio 2020. 
Todo esse trabalho "é desenvolvido com responsabilidade ética e técnica com proteção aos participantes das pesquisas. Entre outros aspectos, leva-se em consideração: riscos aos participantes, retirada de direitos dos participantes, estudos mal elaborados com pesquisadores sem experiência". ${ }^{9}$

Enfim, por mais que se acelerem os estudos, o procedimento da pesquisa científica não é rápido e, possivelmente, os resultados somente surgirão após anos de investigação. Enquanto os pesquisadores se empenham, os índices de mortos e de infectados ascendem e exigem uma resposta imediata da medicina para os tratamentos.

Dessa maneira, reconhecendo-se a excepcionalidade da situação durante o período de pandemia, pacientes infectados com o novo coronavírus recebem medicamentos sem qualquer evidência científica sobre os benefícios na prevenção e no tratamento da doença. É o que acontece, por exemplo, com a prescrição da cloroquina e da hidroxicloroquina - assunto controverso no âmbito científico internacional e que chegou às discussões políticas no país e no mundo. ${ }^{10}$

Como destaca Thamires Pandolfi Cappello, inegável que, em tempos de pandemia, observa-se o incansável esforço de médicos e cientistas para "localizar a cura e/ou a prevenção da respectiva doença. Nesse caso, a busca é pela vacina ou medicamentos eficazes para o tratamento das infecções causadas pelo novo coronavírus (Sars-CoV-2)". ${ }^{11}$

Tecidas as considerações iniciais, é possivel inferir que pesquisas terapêuticas e tratamentos experimentais não necessariamente se confundem. Na realidade, a expressão "tratamento experimental" é utilizada muitas vezes em sentido amplo, abrangendo quaisquer cuidados inovadores, inclusive a pesquisa (que conta com protocolo aprovado previamente por comitê de ética, sujeita à rígida fiscalização estatal e, de certa forma, o resultado positivo beneficia a humanidade). Por vezes, o significado é mais restrito e abrange somente a prática não usual empregada em paciente determinado.

9 Até o dia 10.4.2021, a Conep aprovou 842 protocolos de pesquisas científicas envolvendo a Covid-19, como é o caso de testes utilizando plasma sanguíneo de pacientes já recuperados, o tratamento com associação de cloroquina/hidroxicloroquina e azitromicina, remédios novos e experimentais em estudo (BRASIL. Ministério da Saúde. Conselho Nacional de Saúde. Comissão Nacional de Ética em Pesquisa. Boletim Ética em Pesquisa. Edição Especial Coronavírus (Covid-19). Versão 63.0. Brasília: Conep/CNS/ MS, 2021. Disponível em: http://conselho.saude.gov.br/publicacoes-conep?view=default. Acesso em: 2 maio 2021).

10 CASTRO-SILVA, Igor Luco; MACIEL, Jacques Antonio Cavalcante. Panorama de pesquisas com seres humanos sobre Covid-19 no Brasil. Revista Bioética, Brasília, v. 28, n. 4, p. 655-663, 2020. Disponível em: https://revistabioetica.cfm.org.br/index.php/revista_bioetica/issue/view/75. Acesso em: 2 maio 2021.

11 CAPPELLO, Thamires Pandolfi. Pesquisa clínica e a sua importância no desenvolvimento de fármacos e vacinas em tempo de pandemia. Revista de Direito e Medicina, São Paulo, v. 8, jan./abr. 2021. DTR\2021 \654. 
A título de ilustração, o Superior Tribunal de Justiça (STJ) considera experimental o "tratamento clínico ou cirúrgico incompatível com as normas de controle sanitário ou, ainda, aquele não reconhecido como eficaz pela comunidade científica" ${ }^{12}$ e sedimentou posição no sentido de que "os planos de saúde podem, por expressa disposição contratual, restringir as enfermidades a serem cobertas, sendo-lhes vedado, no entanto, limitar os tratamentos a serem realizados, inclusive os experimentais". ${ }^{13}$ Observa-se a posição permissiva do Tribunal, que emprega a expressão em sentido amplo e não diferencia tratamento experimental de experiência terapêutica ou de pesquisa terapêutica.

Em posição diversa do STJ, o Enunciado oㅜ 26, aprovado na I Jornada de Direito da Saúde do Conselho Nacional de Justiça, em 15.5.2014, dispõe: “É lícita a exclusão de cobertura de produto, tecnologia e medicamento importado não nacionalizado, bem como tratamento clínico ou cirúrgico experimental". ${ }^{14}$ Sem adentrar no questionamento jurídico, observa-se que a locução é usada em sentido lato.

Mais tecnicamente, Sonia Vieira e William Saad Hossne utilizam a terminologia "tratamento experimental" para indicar qualquer tratamento não validado pela comunidade médica: pode ocorrer como uma experiência terapêutica ou como experimento científico. Os textos antigos não discerniam as expressões. ${ }^{15} \mathrm{Com}$ rigorosa precisão, os autores elucidam:

Entende-se como tratamento experimental toda classe de procedimentos ainda não validados pela comunidade médica. Os tratamentos experimentais abrangem tanto o uso de uma droga conhecida, para condições em que não é prescrita, como a administração de terapia médica, cirurgia ou comportamental, ainda não devidamente avaliadas. Os tratamentos experimentais não são, por si sós, um experimento científico. Existe preocupação com os tratamentos experimentais porque a maioria deles está sendo aplicada sem supervisão adequada. Para que sejam validados, os tratamentos experimentais precisam ser incluídos em experimentos científicos. Os experimentos científicos são feitos com a finalidade de produzir conhecimentos. Tais experimentos obedecem a uma estrutura lógica, com base na

12 Informativo, n. 0632, 28 set. 2018. Confira: STJ, Terceira Turma. REsp no 1.721.705/SP. Rel. Min. Nancy Andrighi, j. 28.8.2018. DJe, 6 set. 2018.

13 STJ, Terceira Turma. AgInt no REsp no 1.806.691/SP. Rel. Min. Paulo de Tarso Sanseverino, j. 30.3.2020.

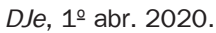

14 CNJ. I Jornada de Direito da Saúde. Disponível em: https://www.cnj.jus.br/programas-e-acoes/forum-dasaude-3/i-jornada-do-forum-nacional-da-saude/. Acesso em: 4 maio 2021.

15 HOSSNE, William Saad; VIEIRA, Sônia. Experimentação com seres humanos. 3. ed. São Paulo: Moderna, [s.d.]. p. 95-96. 
estatística. Nos experimentos clínicos casualizados, a lógica é de comparação. ${ }^{16}$ (Grifos nossos)

Diferentemente, a experiência terapêutica ocorre na prática da medicina, em benefício do paciente. Os autores explicam:

se um médico, na esperança de curar seu paciente, considerar necessário mudar o procedimento terapêutico - como, por exemplo, aumentar a dose da droga prescrita, mudar a droga, combinar o uso da droga com outro tratamento -, estará fazendo uma experiência terapêutica, nunca um experimento científico. ${ }^{17}$

Na área jurídica, Sérgio Ferraz separa as duas situações, ao afirmar que os tratamentos experimentais precedidos por experimentações terapêuticas "são práticas curativas de consequências desconhecidas ou incompletamente conhecidas". Segundo o autor, os tratamentos experimentais diferem

das terapias já admitidas, as quais, se bem que sempre tenham certa margem de experimentalidade - eis que os resultados frequentemente dependem da reatividade individual de cada paciente - repousam sobre coeficientes estatísticos de êxito comprovado, ou sobre riscos devidamente calculados ou calculáveis. ${ }^{18}$

Não se observa um consenso a respeito da terminologia. Contudo, é incontestável a distinção de três situações: a pesquisa (experimento científico), o tratamento experimental e a terapêutica consolidada. Segundo os estudiosos, a priori as inovações devem ocorrer com protocolo de pesquisa, aprovado e fiscalizado pelos órgãos competentes, seguindo rígidos padrões éticos, científicos e jurídicos. Em casos excepcionais, é admitido emprego de tratamentos inovadores em pacientes com estado de saúde sem solução consolidada, como se observa com os infectados pelo coronavírus.

Antes de encerrar o tópico, bastante atual parece ser a discussão a respeito da possibilidade de pessoas saudáveis participarem das pesquisas, com finalidade exclusiva de ampliar o conhecimento em benefício da humanidade. Essas

16 HOSSNE, William Saad; VIEIRA, Sônia. Experimentação com seres humanos. 3. ed. São Paulo: Moderna, [s.d.]. p. 95-96.

17 HOSSNE, William Saad; VIEIRA, Sônia. Experimentação com seres humanos. 3. ed. São Paulo: Moderna, [s.d.]. p. 95-96.

18 FERRAZ, Sérgio. Manipulações biológicas e princípios constitucionais: uma introdução. Porto Alegre: S. A. Fabris, 1991. p. 41 
pesquisas, por não trazerem benefícios diretos ao participante, são as que suscitam maiores questionamentos éticos e jurídicos, inclusive para efeitos de responsabilidade civil. A questão é ainda mais controversa quando se refere à população vulnerável, como é o caso de crianças e idosos.

Genival Veloso de França entende ser uma pesquisa lícita quando: a) realizada, como último recurso, em um doente cuja terapêutica convencional tenha falhado; b) com finalidade curativa, em benefício do próprio paciente. 0 autor repudia experimentação com o simples caráter especulativo, pois ninguém tem o direito de permitir ou de exigir que alguém se submeta a pesquisas científicas com eventuais danos à vida e à saúde. ${ }^{19}$

Maria Helena Diniz entende que as pesquisas biomédicas devem ter finalidade terapêutica, não podendo ser realizadas em pessoas sadias. "A pesquisa somente pode ser levada a efeito em doente para atender a seu próprio interesse, enfrentando um mal que coloque sua vida em risco, numa tentativa de salvá-la, restabelecer sua saúde ou pelo menos aliviar sua dor ou sofrimento". ${ }^{20}$

Na realidade, a Declaração de Helsinque acata a diferença entre experimento terapêutico e não terapêutico, sendo que o primeiro vislumbra beneficiar tanto o participante (diretamente), como a humanidade (indiretamente). Resoluções do Conselho Federal de Medicina (CFM) e do Conselho Nacional de Saúde (CNS), na mesma linha do documento internacional, preveem testes em voluntários saudáveis.

Portanto, a respeito do novo coronavírus, entende-se que as pesquisas terapêuticas, por beneficiarem diretamente o participante ou um grupo de participantes, são mais facilmente aceitáveis. As investigações não terapêuticas, como deixam de favorecer o envolvido, encontram-se sujeitas a maior controle, mas também são lícitas. O que se condena eticamente são procedimentos meramente especulativos, efetuados apenas com curiosidade científica, carentes de qualquer proveito ou benefício social. Como ensina João Vaz Rodrigues, a perspectiva de salvar um significativo contingente de vidas não legitima a arbitrariedade científica no precioso domínio individual do ser humano. ${ }^{21}$

Em termos jurídicos, é essencial que as três situações acima sejam diferenciadas, visto que a legislação aplicada não é a mesma, particularmente a respeito do consentimento e da responsabilidade civil.

19 FRANÇA, Genival Veloso de. Direito médico. 12. ed. Rio de Janeiro: Forense, 2014. p. 475.

20 DINIZ, Maria Helena. O estado atual do biodireito. 10. ed. São Paulo: Saraiva, 2017. p. 570.

21 RODRIGUES, João Vaz. O consentimento informado para o acto médico no ordenamento jurídico português.

Elementos para o estudo da manifestação de vontade. Coimbra: Coimbra, 2001. p. 159-160. 


\section{A licitude dos tratamentos experimentais}

Como explicado no tópico anterior, nos primórdios, a experimentação era feita com finalidade exclusivamente terapêutica: buscava-se a melhor forma de tratar o paciente, em seu próprio benefício. Com o progresso, a experimentação adquiriu caráter científico: hoje, experimentam-se novos tratamentos em pacientes para ampliar o conhecimento, não necessariamente com finalidade terapêutica. ${ }^{22}$

$\mathrm{Na}$ realidade, ao longo dos séculos, a investigação em seres humanos tem sido realizada no mundo todo, "com diferentes padrões de ética e de qualidade". ${ }^{23}$ A experiência nazista e os julgamentos do Tribunal de Nuremberg podem ser lembrados como sinal de alerta à vigilância social contra os excessos científicos. ${ }^{24}$ Como reação, documentos internacionais contendo normas e/ou diretrizes delimitaram referidos estudos. Os três principais documentos são: Código de Nuremberg, Declaração de Helsinque e Diretrizes Éticas Internacionais para a Pesquisa Biomédica em Seres Humanos.

No Brasil, é recente o enfrentamento da questão, que se orienta por documentos internacionais. Como afirma Antônio Chaves, a primeira norma a versar sobre ética em pesquisa com seres humanos foi a Resolução no 001/1988, do Conselho Nacional de Saúde..$^{25}$ Como essa normativa não estava sendo cumprida, aprovou-se a Resolução do Conselho Nacional de Saúde (CNS) oㅡ 196/1996, fundamentada em extensa documentação ética e jurídica, que se converteu em referência e estimulou a formação dos comitês de ética em pesquisa. Ademais, outras resoluções específicas e complementares foram publicadas. ${ }^{26}$

Atualmente, a principal normativa vigente em pesquisa com seres humanos é a Resolução no 466/2012, e as fases da pesquisa clínica estão definidas na Resolução no 251/1997, ambas do Conselho Nacional de Saúde (CNS). Por sua vez, a Resolução oㅗ 1.982/2012, publicada pelo Conselho Federal de Medicina (CFM), regulamenta "os critérios de protocolo e avaliação para o reconhecimento de novos procedimentos e terapias médicas".

22 HOSSNE, William Saad; VIEIRA, Sônia. Experimentação com seres humanos. 3. ed. São Paulo: Moderna, [s.d.]. p. 30.

23 HOSSNE, William Saad; VIEIRA, Sônia. Experimentação com seres humanos. 3. ed. São Paulo: Moderna, [s.d.]. p. 30.

24 Sobre a regulação da experimentação humana, confira: CASCAIS, António Fernando. A experimentação humana e a crise da auto-regulação da biomedicina. In: RIBEIRO, Gustavo Pereira Leite; TEIXEIRA, Ana Carolina Brochado (Coord.). Bioética e direitos da pessoa humana. Belo horizonte: Del Rey, 2012. p. 27-52.

25 CHAVES, Antônio. Pesquisa em seres humanos. Revista de Informação Legislativa, Brasília, v. 27, n. 108 , p. 229-252, out./dez. 1990. p. 230.

26 FERNANDES, Márcia Santana; GOLDIM, José Roberto; MAFRA, Márcia Robalo; MORAIS, Leonardo Stoll. A responsabilidade civil do pesquisador "responsável" nas pesquisas científicas envolvendo seres humanos e a Resolução CNS 466/2012. Revista de Direito Civil Contemporâneo, São Paulo, ano 2, v. 5, p. 97-118, out./dez. 2015. 
Segundo as mencionadas resoluções, os protocolos para as pesquisas devem ser submetidos, avaliados e aprovados pelo Sistema CEP/Conep. Observase, ademais, a fiscalização da conduta ética dos médicos envolvidos na pesquisa pela Comissão de Ética Médica, registrada no Conselho Regional de Medicina (CRM). O consentimento livre e esclarecido do participante é requisito essencial para o procedimento.

Ao contrário da pesquisa com animais, ${ }^{27}$ o Brasil não dispõe de lei específica sobre pesquisa com seres humanos, ${ }^{28}$ assunto que se encontra regrado em resoluções do Conselho Nacional de Saúde (CNS) e do Conselho Federal de Medicina (CFM). A regulamentação se dá por ato infralegal, o que não afasta os direitos prescritos na Constituição Federal e no Código Civil. É o que esclarece Eduardo Tomasevisius Filho: ${ }^{29}$

A disciplina ética a respeito das pesquisas com seres humanos está diretamente interligada com o Código Civil. Em razão de sua especificidade, como também da falta de juridicidade da Declaração de Helsinque e da natureza infralegal da Resolução CNS n. 466/2012, esses diplomas normativos não poderiam contemplar assuntos relacionados à personalidade jurídica, à capacidade de agir, aos direitos da personalidade e à responsabilidade civil. Por sua vez, o Código Civil, em razão de sua generalidade não poderia contemplar, detaIhadamente, aspectos específicos relacionados às pesquisas com seres humanos. No entanto, pesquisadores devem conhecer as regras contidas no Código Civil, uma vez que não estão imunes a sua incidência. É o Código Civil que dará eficácia necessária àqueles documentos normativos, que, em última análise, voltam-se à proteção da pessoa humana.

As pesquisas com seres humanos devem respeitar os direitos da personalidade - como a vida, a integridade física e a integridade psíquica -, os quais são direitos indisponíveis. Mesmo em um cenário de flexibilização de regras éticas, como se verifica nas sucessivas

$\overline{27}$ No Brasil, a Lei Federal № 11.794, de 8.10.2008, regulamenta o inc. VII, do §1ํㅡ, do art. 225 da Constituição Federal e estabelece procedimentos para o uso científico de animais. 0 art. 32, §1ํㅡ, da Lei no 9.605, de 12.2.1998, proíbe experiências dolorosas ou cruéis em animais vivos, ainda que para fins didáticos ou científicos, quando existem recursos alternativos. Sobre o assunto, confira: NAMBA, Edison Tetsuzo. Manual de bioética e biodireito. 2. ed. São Paulo: Atlas, 2015. p. 120-121.

28 Tramita na Câmara dos Deputados o Projeto de Lei no 7.082/2017, antigo PLS no 200/2015, que dispõe sobre a pesquisa clínica com seres humanos e institui o Sistema Nacional de Ética em Pesquisa Clínica com Seres Humanos. O projeto é muito criticado por retirar direitos dos doentes nas pesquisas, além de acabar com a independência da Conep.

29 TOMASEVICIUS FILHO, Eduardo. O Código Civil brasileiro na disciplina da pesquisa com seres humanos. Revista de Direito Sanitário, São Paulo, v. 16, n. 2, p. 116-146, jul./out. 2015. p. 144. 
modificações da - [sic], não há como o pesquisador eximir-se da responsabilidade civil em caso de lesões aos direitos da personalidade ocasionados aos participantes de uma pesquisa, além das sanções aplicáveis pelos CEPs. (Grifos nossos)

Ou seja, sobre as pesquisas com seres humanos, incide todo o arcabouço jurídico vigente no país, entre os quais a Constituição Federal de 1988, o Código Civil, o Código Penal e as leis esparsas. No que concerne ao Código Civil, devem ser respeitadas as normas relativas aos direitos da personalidade, à personalidade, à capacidade, aos negócios jurídicos e, particularmente, à responsabilidade civil. ${ }^{30}$

No entanto, cumpre advertir que as inovações científicas e tecnológicas acarretam "uma ruptura com antigos enquadramentos juscivilísticos de alguns institutos perante as novas situações jurídicas, que requerem do aplicador do direito um olhar diferenciado", voltado para salvaguardar os interesses da pessoa em concreto. ${ }^{31} \mathrm{Em}$ se tratando de situação existencial, atrai-se uma principiologia própria como a gratuidade do ato, do consentimento qualificado, da confiança e da autorresponsabilidade. ${ }^{32}$

Situação um pouco mais complexa envolve o tratamento experimental que se verifica fora do protocolo de pesquisa e ausente de aprovação pelo comitê de ética. Há uma divergência científica e jurídica a respeito de sua licitude.

Em âmbito interno, o art. 100 do Código de Ética Médica estabelece ser vedado ao médico “Deixar de obter aprovação de protocolo para a realização de pesquisa em seres humanos, de acordo com a legislação vigente”. Por sua vez, o art. 102, parágrafo único, esclarece que "A utilização de terapêutica experimental é permitida quando aceita pelos órgãos componentes e com o consentimento do paciente, ou de seu representante legal, adequadamente esclarecido da situação e das possíveis consequências". ${ }^{33}$ No mesmo sentido, na Resolução no 1.982/2012, a autarquia deixa claro que inovações somente podem ocorrer

30 TOMASEVICIUS FILHO, Eduardo. O Código Civil brasileiro na disciplina da pesquisa com seres humanos. Revista de Direito Sanitário, São Paulo, v. 16, n. 2, p. 116-146, jul./out. 2015. p. 145.

31 TEIXEIRA, Ana Carolina Brochado; PEREIRA, Paula Moura Francesconi de Lemos. A participação de crianças e adolescentes em ensaios clínicos: uma reflexão baseada nos princípios do melhor interesse, solidariedade e autonomia. Revista Brasileira de Direito Civil - RBDCivil, Belo Horizonte, v. 9, p. 58-80, jul./set. 2016. Disponível em: https://rbdcivil.ibdcivil.org.br/rbdc/article/view/54. Acesso em: 3 maio 2021.

32 TEIXEIRA, Ana Carolina Brochado. Autonomia existencial. Revista Brasileira de Direito Civil - RBDCivil, Belo Horizonte, v. 16, p. 75-104, abr./jun. 2018. Disponível em: https://rbdcivil.ibdcivil.org.br/rbdc/article/ view/232. Acesso em: 3 maio 2021.

33 BRASIL. Conselho Federal de Medicina. Resolução CFM nำ2.217/2018, que aprova o Código de Ética Médica. Disponivel em: http://portal.cfm.org.br/index.php?option=com_normas\&tipo\%5B\%5D=R\&uf=\&numero=\& ano=\&assunto=1963\&texto=. Acesso em: 25 abr. 2020. 
sob forma de pesquisa, com participações do comitê de ética em pesquisa e da comissão de ética médica.

Em 2019, ao ser consultado pela 3a vara Cível da Comarca de Americana (São Paulo) sobre a realização de transplante de medula óssea para o tratamento da doença de Crohn, o Conselho Federal de Medicina esclareceu que se tratava de procedimento médico promissor, ainda experimental, "só podendo ser realizado dentro de protocolos clínicos de pesquisa, de acordo com as normas do sistema CEP/CONEP". ${ }^{34} \mathrm{E}$, em outro caso, consultado sobre a ozonioterapia na prática clínica, o Conselho concluiu que consistia em "procedimento experimental para a prática médica, só podendo ser realizada sob protocolos clínicos de acordo com o Sistema CEP/CONEP". 35

Assim, nos termos do código deontológico, o médico deve utilizar todos os meios disponíveis de saúde e de prevenção, diagnóstico e tratamento de doenças, a seu alcance, em favor do paciente, desde que cientificamente reconhecidos (art. 32). ${ }^{36}$ Com intuito de preservar direitos fundamentais, procedimentos sem amparo científico não podem ser realizados por médico sem projeto sistematizado e aprovado pelos conselhos de ética competentes, sob pena de caracterizar imprudência do profissional.

No entanto, reconhecendo a excepcionalidade da situação e durante o período de pandemia da Covid-19, o Conselho Federal de Medicina, no Parecer nำ 4/2020, autorizou a prescrição de cloroquina e de hidroxicloroquina em pacientes, embora ausentes as evidências científicas sobre os benefícios na prevenção e no tratamento da doença e mesmo diante dos relatos de efeitos adversos fatais em pacientes sob uso da droga-teste. ${ }^{37}$

Com efeito, a mencionada prescrição caberá ao médico, em decisão compartilhada com o paciente, após este ser informado que não existe trabalho científico, com ensaio clínico adequado, feito por pesquisadores reconhecidos e publicado em revistas científicas de alto nível que comprove qualquer benefício do uso das drogas para o tratamento da Covid-19. Ademais, o profissional deverá apontar os

34 BRASIL. Conselho Federal de Medicina. Processo Consulta no 52019. Parecer CFM n 6/2019. Relator: Lúcio Flávio Gonzaga Silva. 15 fev. 2019. Disponível em: https://sistemas.cfm.org.br/normas/visualizar/ pareceres/BR/2019/6. Acesso em: 25 abr. 2020.

35 BRASIL. Conselho Federal de Medicina. Processo Consulta no 10/218. Parecer CFM no 9/2018. Relator: Leonardo Sérvio Luz. 19 abr. 2018. Disponível em: https://sistemas.cfm.org.br/normas/visualizar/ pareceres/BR/2018/9 Acesso em: 25 abr. 2020.

36 Confira Resolução CFM no 2.217/2018, art. 32.

37 CASTRO-SILVA, Igor Luco; MACIEL, Jacques Antonio Cavalcante. Panorama de pesquisas com seres humanos sobre Covid-19 no Brasil. Revista Bioética, Brasília, v. 28, n. 4, p. 655-663, 2020. p. 659. Disponível em: https://revistabioetica.cfm.org.br/index.php/revista_bioetica/issue/view/75. Acesso em: 2 maio 2021. 
efeitos colaterais possíveis e, após os esclarecimentos, obter o consentimento livre e esclarecido do próprio infectado ou de seus familiares, quando for o caso.

Em suma, pelo entendimento do Conselho Federal de Medicina, as alternativas experimentais somente podem ser realizadas com aprovação prévia de Comitê de Ética em Pesquisa (CEP) e do Comitê de Ética Médica, nos termos das resoluções correspondentes, mediante assinatura de termo de consentimento livre e esclarecido (TCLE) e sem qualquer ônus financeiro para o paciente. No entanto, em razão "da excecionalidade da situação e durante o período declarado da pandemia, não cometerá infração ética o médico que utilizar a cloroquina ou hidroxicloroquina, nos termos acima expostos, em pacientes portadores da COVID-19". ${ }^{38}$

No direito, em geral, é possível perceber que a licitude das alternativas experimentais divide as opiniões. Há juristas refratários aos tratamentos experimentais fora dos protocolos de pesquisa, os quais enfatizam a responsabilidade civil do profissional que deixa de observar os padrões cientificamente comprovados pela ciência.

É o que defende Rui Stoco, ao alegar que a "'prática de experiências médicas com técnicas não aceitas' é causa diversa de erro médico, que pode conduzir à obrigação de indenizar". E complementa: "Assim, o profissional obriga-se apenas a empregar todo o seu esforço e atenção e a utilizar técnicas consagradas e aceitas, não devendo fazer experimentos ou experiências, dele se exigindo apenas o melhor tratamento e a diligência necessária". 39

Heloisa Helena Barboza esclarece que "Todo procedimento de qualquer natureza envolvendo o ser humano, cuja aceitação não esteja ainda consagrada na literatura científica, será considerado como pesquisa e, portanto, deverá obedecer às diretrizes da Resolução no 196/96". Assim, a autora segue o posicionamento geral do CFM, ao entender que os tratamentos experimentais deverão seguir a Resolução CNS no 466/2012. Ou seja, somente são admitidos tratamentos experimentais sob a forma de pesquisa científica. ${ }^{40}$

Identifica-se uma corrente que sustenta a relevância desses tratamentos quando as terapêuticas convencionais são inexistentes ou ineficazes, desprezando a afirmação de que os efeitos desconhecidos podem comprometer os valores

38 BRASIL. Conselho Federal de Medicina. Parecer CFM n 4/2020 (tratamento de pacientes portadores de COVID-19 com cloroquina e hidroxicloroquina). Disponível em: https://sistemas.cfm.org.br/normas/ visualizar/pareceres/BR/2020/4. Acesso em: 2 maio 2021.

39 STOCO, Rui. Tratado de responsabilidade civil: doutrina e jurisprudência. 8. ed. revista, atualizada e ampliada com Comentários ao Código Civil. São Paulo: Revista dos Tribunais, 2011. p. 625.

40 BARBOZA, Heloisa Helena. Responsabilidade civil em face das pesquisas em seres humanos: efeitos do consentimento livre e esclarecido. In: MARTINS-COSTA, Judith; MÖLLER, Letícia Ludwig (Org.). Bioética e responsabilidade. Rio de Janeiro: Forense, 2009. p. 218. 
essenciais dos pacientes. Pelo proveito oportunizado, os novos métodos devem ser incentivados, respeitando-se os limites éticos e legais.

É a direção tomada por André Gonçalo Dias Pereira, que ressalta apoiarem o avanço da medicina os princípios éticos e jurídicos. Rejeitável o aventurismo, mas admissível a realização de ensaios clínicos devidamente controlados (pesquisa) e as inovações terapêuticas. Aliás, segundo o professor da Universidade de Coimbra, o próprio princípio da precaução pode impor o dever de submissão a riscos, quando não existe cuidado consolidado e é presente a possibilidade de morte, aceitando-se tratamento ou medicamento ainda não validado, mas com indícios da eficácia. ${ }^{41}$

No cenário pátrio, José de Aguiar Dias explica que o médico tem

o direito de inovar e até de empregar tratamento por analogia, mas é preciso que suas tentativas sejam conscienciosas e escrupulosamente orientadas pelos princípios da ciência, não meros ensaios puramente aleatórios, pois "o corpo humano não é matéria bruta, destinada a experiências, nem mesmo no campo puramente científico". ${ }^{42}$

E, completando o raciocínio do eminente civilista, esclarece Fabrício Zamprona Matielo que essa "circunstância afastará a possibilidade de responsabilização civil, salvo erro crasso e notório, porque o objetivo - preservação da vida e dignidade - justificou o recurso aos meios empregados no combate à patologia". ${ }^{43}$

No tocante à jurisprudência, os tribunais revelam um posicionamento permissivo às inovações. Como afirmado anteriormente, o Superior Tribunal de Justiça sedimentou o entendimento favorável ao decidir que o seguro ou plano de saúde deve custear terapêutica experimental, desde que haja indicação médica e os médicos que acompanham o quadro clínico do paciente "atestem a ineficácia ou a insuficiência dos tratamentos indicados convencionalmente para a cura ou controle eficaz da doença". ${ }^{44}$ Importante ressaltar que o STJ não diferencia tratamento experimental, experiência terapêutica ou pesquisa terapêutica.

41 PEREIRA, André Gonçalo Dias. O consentimento informado na relação médico-paciente: estudo de direito civil. Coimbra: Centro de Direito Biomédico, Faculdade de Direito da Universidade de Coimbra, 2004. p. 455-456.

42 DIAS, José de Aguiar. Da responsabilidade civil. 12. ed. revista, atualizada de acordo com o Código Civil de 2002, e aumentada por Rui Berford Dias. Rio de Janeiro: Lumen Juris, 2012. p. 289.

43 Ressalta-se que os experimentos científicos são vedados para patologias controláveis por meio de medicamentos ou aparelhagens de eficácia comprovada, pois do contrário "haveria exposição da pessoa a riscos inúteis” (MATIELO, Fabrício Zamprogna. Responsabilidade civil do médico. Porto Alegre: Sagra Luzzatto, 1998. p. 115).

44 Informativo, n. 0551, 3 dez. 2014. Confira: STJ, Quarta Turma. REsp no 1.279.241/SP. Rel. Min. Maria Isabel Gallotti, Rel. p/ Acórdão Min. Raul Araújo, j. 2.10.2014. DJe, 7 nov. 2014. 
Em sentido oposto, cita-se o Enunciado no 9, aprovado na I Jornada de Direito da Saúde do Conselho Nacional de Justiça (CNJ), em 15.5.2014:

As ações que versem sobre medicamentos e tratamentos experimentais devem observar as normas emitidas pela Comissão Nacional de Ética em Pesquisa (Conep) e Agência Nacional de Vigilância Sanitária (Anvisa), não se podendo impor aos entes federados provimento e custeio de medicamento e tratamentos experimentais. ${ }^{45}$

Aliás, o enunciado mencionado e outros aprovados nas Jornadas de Direito da Saúde demonstram a orientação do CNJ, no sentido de se evitarem tratamentos experimentais sem observância da Resolução CNS no 466/2012 e das resoluções da Anvisa.

Na Ação Direta de Inconstitucionalidade № 5.501/DF, prevaleceu o posicionamento do relator, Ministro Marco Aurélio, que considerou ser inconstitucional a distribuição de medicamento antes de estudos comprobatórios de sua eficácia, em razão da possibilidade de comprometer situações constitucionais fundamentais como o direito à saúde (arts. 6o e 196), o direito à segurança e à vida (art. 5으, caput), e o princípio da dignidade da pessoa humana (art. 1ํㅡ, inc. III). No voto, o ministro discorre sobre o fato de que a esperança depositada pela sociedade nos medicamentos não pode se distanciar da ciência. ${ }^{46}$

É evidente que as experimentações terapêuticas merecem respeito pelo fato de representarem, em muitas situações, a única possibilidade de que o paciente dispõe para ser curado ou, mesmo, para sobreviver. Considerando os direitos constitucionalmente garantidos, a busca pela preservação da vida e da saúde deve ser objeto da ciência, incentivada pelo Estado e pela sociedade.

Todavia, "existe a necessidade de que o ser humano não venha a ser utilizado como cobaia em situações que possam ser de outro modo controladas". ${ }^{47}$ Como o tratamento experimental não revela comprovação científica com segurança e eficácia, inegáveis são os riscos ao paciente, e a ausência de controle pelos comitês de ética exige acentuada prudência na sua prática.

Com efeito, ante a ausência de critérios normativos, o item 37 da Declaração de Helsinque fornece adequadas orientações, no preenchimento da lacuna legal:

45 CNJ. I Jornada de Direito da Saúde. Disponível em: https://www.cnj.jus.br/programas-e-acoes/forum-dasaude-3/i-jornada-do-forum-nacional-da-saude/. Acesso em: 4 maio 2021.

46 STF, Tribunal Pleno. ADI no 5.501 MC. Rel. Min. Marco Aurélio, j. 19.5.2016, Processo Eletrônico DJe-168 divulg. 31.7.2017, public. 1ํ.8.2017.

47 MATIELO, Fabrício Zamprogna. Responsabilidade civil do médico. Porto Alegre: Sagra Luzzatto, 1998. p. 115. 
No tratamento de um determinado paciente, onde intervenções comprovadas não existem ou outras intervenções conhecidas se mostram inefetivas, o médico, depois de buscar conselho especializado, com consentimento informado do paciente ou de representante legalmente autorizado, pode usar uma intervenção não comprovada se em seu julgamento ela oferece esperança de salvar a vida, restabelecer a saúde ou aliviar o sofrimento. Esta intervenção deve, em seguida, tornar-se objeto de pesquisa desenhada para avaliar sua segurança e eficácia. Em todos os casos, a nova informação deve ser registrada e, quando apropriado, tornada disponível publicamente.

0 documento internacional reflete $\mathrm{o}$ acautelamento exigido pela preocupante situação: "aconselhando" o uso somente quando as intervenções comprovadas não existirem, ou outras intervenções conhecidas se mostrarem ineficazes para salvar a vida, restabelecer a saúde ou aliviar o sofrimento. A esperança de benefícios deve superar a possibilidade de danos e há de ser consultado previamente o conselho de ética médica. Eis um norteador para os tratamentos de pacientes com Covid-19.

Ademais, o princípio bioético da autonomia deve estar presente, com toda a força, diante da excepcionalidade, "sendo as inovações terapêuticas lícitas em sede de controlo da boa prática médica, o que se impõe especialmente acentuar é o dever de esclarecimento quando o médico recorra a estes métodos ousados e ainda não consagrados nos standards internacionais". Ou melhor dizendo, "um consentimento informado reforçado vem colmatar ou compensar as dúvidas que poderiam residir em sede de leges artis (stricto senso)". ${ }^{48}$

Em experimentações terapêuticas, a princípio, afasta-se a responsabilidade civil dos profissionais e dos hospitais, salvo erro médico grosseiro, visto que o intuito de privilegiar a vida e a saúde justifica a adoção dos meios empregados no combate da patologia. É o que será adiante demonstrado.

Adverte-se que o estudo da responsabilidade civil deverá considerar a diferença entre pesquisa terapêutica (estudo científico) e experiência terapêutica (prática sem eficácia comprovada em benefício de determinado paciente). Esta última encontra resistência dos conselhos de medicina, divergência na doutrina e na jurisprudência: enquanto, para uns, inovar em benefício do paciente é direito (e até dever) do médico, outros a consideram imprudência do profissional. Contudo, a resistência aos tratamentos experimentais parece estar presente em épocas

48 PEREIRA, André Gonçalo Dias. O consentimento informado na relação médico-paciente: estudo de direito civil. Coimbra: Centro de Direito Biomédico, Faculdade de Direito da Universidade de Coimbra, 2004. p. 456. 
de normalidade, uma vez que a pandemia impõe a flexibilização dos standards éticos, científicos e jurídicos.

Antes de adentrar ao tema da responsabilidade civil, cabem algumas considerações sobre o consentimento livre e esclarecido nos tratamentos experimentais.

\section{0 termo de consentimento livre e esclarecido (TCLE) do paciente/participante}

Quando se fala em tratamentos experimentais com seres humanos e, aqui no trabalho, com enfoque à Covid-19, deve-se ter em mente uma proteção central da pessoa humana, sua dignidade, sua autonomia em se submeter ao tratamento, mas sem perder de vista que, no momento em que a pessoa aceita um tratamento experimental, ela está em situação de vulnerabilidade. ${ }^{49}$ Sobre esse aspecto, esclarece Judith Martins-Costa aumentar a chance de desrespeito, pois o sentido etimológico de vulnerabilidade significa "ferida", de maneira que a vulnerabilidade é a susceptibilidade a ser ferido. ${ }^{50}$

No Brasil, algumas vacinas contra a Covid-19 já dispõem de registro definitivo junto à Anvisa e podem ser comercializadas, distribuídas e utilizadas pela população, por terem segurança, qualidade e eficácia comprovadas. Outras, contam com autorização do órgão para uso emergencial - são experimentais, mas dispõem de informações suficientes que justificam a aplicação durante a emergência sanitária. Enfim, há vacina que teve a importação em caráter excepcional rejeitada por não indicar dados consistentes e confiáveis. Inquestionável que "do ponto de vista epidemiológico as vacinas destacam-se pelo seu alto grau de eficiência e pelo custo-benefício e, por isso, o grande esforço mundial em desenvolver rapidamente uma imunização contra a Covid-19". ${ }^{51}$

Observa-se também a autorização da Anvisa para ensaios clínicos referentes a medicamentos voltados à prevenção ou ao tratamento da doença. Mas, enquanto pendente a demonstração científica de segurança e eficácia dos fármacos,

49 Sobre a vulnerabilidade, explica o art. 8o da Declaração Universal sobre Bioética e Direitos Humanos: “A vulnerabilidade humana deve ser levada em consideração na aplicação e no avanço do conhecimento científico, das práticas médicas e de tecnologias associadas. Indivíduos e grupos de vulnerabilidade específica devem ser protegidos e a integridade individual de cada um deve ser respeitada" Organização das Nações Unidas para Educação, Ciência e a Cultura. Declaração universal sobre bioética e direitos humanos [Internet]. Genebra: Unesco; 2005. Disponível em: http://bit.ly/2kgv9lt. Acesso em: 21 jul. 2020.

50 MARTINS-COSTA, Judith. Prefácio a CEZAR, Denise Oliveira. Pesquisa com medicamentos. Aspectos bioéticos. In: MARTINS-COSTA, Judith. Modelos de direito privado. São Paulo: Marcial Pons, 2014. p. 77.

51 SCHAEFER, Fernanda. Vacinas e Covid-19: O que esperar? Migalhas, 24 ago. 2020. Disponível em: https://www.migalhas.com.br/coluna/direito-e-bioetica/332321/vacinas-e-covid-19--o-que-esperar. Acesso em: 30 abr. 2021. 
incentiva-se o isolamento social a fim de evitar a propagação do vírus invisível, prevenindo-se a contaminação. E os doentes continuam sendo tratados de forma "experimental". ${ }^{52}$

Segundo Roberto H. Pôrto Nogueira, o médico possui prerrogativa de prescrever medicamentos, cabendo à Anvisa fazer uma limitação quando dos registros desses medicamentos e, uma vez autorizada a comercialização para determinado fim, outras indicações são possíveis, em princípio, lícitas, sendo ilícitas as que sequer foram autorizadas, em qualquer hipótese, para comercialização no território nacional. ${ }^{53}$

Especificamente sobre a hidroxicloroquina e a cloroquina, mesmo sem a certeza sobre sua eficácia para a Covid-19, foi editado o Parecer CFM no 4/2020 autorizando a prescrição pelos médicos, em situação excepcional. 0 uso desses agentes farmacológicos para indicação diversa daquela que foi autorizada pelo órgão regulatório é denominado off label.

Diante de tantas incertezas, sabe-se que um documento fundamental para os pacientes que se submetem às experimentações é o termo de consentimento livre e esclarecido (TCLE). Como já mencionado, o TCLE é exigido em pesquisas que envolvam seres humanos e está regulamentado pelas resoluções no 466/12 e no 510/16 do CNS. Seu conteúdo segue a Recomendação CFM no 1/2016, no item 9.1.3, e trata-se de um "documento escrito, ${ }^{54}$ pelo qual o paciente consente com a prática médica, exercendo, assim, sua autonomia privada". ${ }^{55}$

Conhecido nos procedimentos consolidados como "consentimento informado", o documento significa um processo de troca de informações entre médico e paciente e permite a participação efetiva deste em seu tratamento. ${ }^{56}$ Ressalta-se

52 O Brasil ultrapassou, até o mês de maio de 2021, quatrocentos mil mortos pela doença. Sobre os principais sintomas da doença, afirma Nogueira serem: febre, tosse e cansaço e, em pacientes graves, as complicações evoluem para desconforto respiratório agudo, lesão cardíaca aguda, infecção secundária e danos aos tecidos e órgãos pulmonares (NOGUEIRA, Roberto Pôrto. Responsabilidade civil do médico na prescrição off label de medicamentos para a Covid-19. In: MONTEIRO FILHO, Carlos E. do Rêgo; ROSENVALD, Nelson; DENSA, Roberta (Coord.). Coronavírus e responsabilidade civil: impactos contratuais e extracontratuais. Indaiatuba: Foco, 2020. p. 285).

53 NOGUEIRA, Roberto Pôrto. Responsabilidade civil do médico na prescrição off label de medicamentos para a Covid-19. In: MONTEIRO FILHO, Carlos E. do Rêgo; ROSENVALD, Nelson; DENSA, Roberta (Coord.). Coronavírus e responsabilidade civil: impactos contratuais e extracontratuais. Indaiatuba: Foco, 2020. p. 288-289.

54 A análise de acórdãos de cortes no Brasil demonstra que "O Judiciário considera somente TCl escritos, por isso os designados como verbais ou não encontrados foram tidos como ausentes". Confira: MANZINI, Merlei Cristina; MACHADO FILHO, Carlos D'Apparecida Santos; CRIADO, Paulo Ricardo. Termo de consentimento informado: impacto na decisão judicial. Revista de Bioética, Brasília, v. 28, n. 3, p. 517-521. p. 519. Disponível em: https://revistabioetica.cfm.org.br/index.php/revista_bioetica/issue/view/74. Acesso em: 3 maio 2020.

55 SÁ, Maria de Fátima Freire de; SOUZA, lara Antunes de. Termo de consentimento livre e esclarecido e responsabilidade civil do médico e do hospital. In: ROSENVALD, Nelson. MENEZES, Joyceane Bezerra de; DADALTO, Luciana (Coord.). Responsabilidade civil e medicina. 9. ed. Indaiatuba: Foco, 2020. p. 57.

56 É pelo termo de consentimento livre e esclarecido que a pessoa atua e decide e, portanto, o documento reproduz o acordo de vontades entre o médico e o paciente após o adimplemento do dever de informar, 
que a decisão precisa ser consciente, visto que a manifestação só será válida se o médico explicar de forma clara os benefícios e riscos do procedimento. ${ }^{57}$

Segundo Maria de Fátima Freire de Sá e lara Antunes de Souza, o termo nasce da necessidade de proteger o paciente, mas também pode ser um meio jurídico limitador da responsabilidade civil do médico e do hospital. ${ }^{58}$ Assim, o termo tem duas finalidades: "jurídica, para eventual defesa do profissional e ética, como processo de esclarecimento na relação entre médico e paciente [...]".59

Analisaram-se alguns TCLEs disponíveis na internet que versam sobre a Covid-19, a fim de aferir o respectivo conteúdo. O termo disponível para utilização da hidroxicloroquina/cloroquina no tratamento da preocupante doença traz os pontos a seguir delineados.

O primeiro ponto refere-se aos dados do paciente com a localização do leito em que está internado. Após, o item “diagnóstico e tratamento” indica a Covid-19, com a sugestão para tratamento com uso da hidroxicloroquina ou cloroquina. Em seguida, como um dos principais assuntos do termo, tem-se a explicação dos procedimentos, benefícios, riscos e alternativas. ${ }^{60} \mathrm{O}$ paciente mostra-se ciente de que será submetido ao tratamento ainda experimental, de que não existe a comprovação da eficácia do tratamento e dos eventuais efeitos colaterais. Finalmente, o termo dispõe da autorização do paciente/responsável, ciente dos riscos mencionados, aceitando o tratamento e explicitando que suas dúvidas foram sanadas. Após, o documento traz a declaração do médico responsável, afirmando ter informado o paciente ou sua família sobre o tratamento e esclarecido as dúvidas. ${ }^{61}$

Na crise epidêmica, o TCLE é um documento importante para esclarecer o paciente infectado sobre algumas possiveis consequências que ele pode vir a sofrer em virtude do tratamento não convencional a que se submete. “É o dever de o profissional

bem como legitima a ação do médico, já que o ponto de referência é o gozo de direitos da personalidade pelo paciente. Sobre o assunto, confira: KONDER, Carlos Nelson; TEIXEIRA, Ana Carolina Brochado. Crianças e adolescentes na condição de pacientes médicos: desafios da ponderação entre autonomia e vulnerabilidade. Pensar, Fortaleza, v. 21, n. 1, p. 70-93, jan./abr. 2016. p. 77. Disponível em: https:// periodicos.unifor.br/rpen/issue/view/400. Acesso em: 3 maio 2021.

57 CASTRO, Fernanda de; QUINTANA, Alberto Manuel; MÜNCHEN, Mikaela Aline Bade. Termo de consentimento livre e esclarecido na assistência à saúde. Revista Bioética, Brasília, v. 28, n. 3, 2020. p. 523.

58 SÁ, Maria de Fátima Freire de; SOUZA, lara Antunes de. Termo de consentimento livre e esclarecido e responsabilidade civil do médico e do hospital. In: ROSENVALD, Nelson. MENEZES, Joyceane Bezerra de; DADALTO, Luciana (Coord.). Responsabilidade civil e medicina. 9. ed. Indaiatuba: Foco, 2020. p. 57.

59 CASTRO, Fernanda de; QUINTANA, Alberto Manuel; MÜNCHEN, Mikaela Aline Bade. Termo de consentimento livre e esclarecido na assistência à saúde. Revista Bioética, Brasília, v. 28, n. 3, 2020. p. 523.

60 TCLE para uso da hidroxicloroquina ou cloroquina no tratamento da Covid-19. Hospital Cárdio Pulmonar. Disponível em: http://www.cardiopulmonar.com.br/espacomedico/wp-content/uploads/2020/03/Termode-Ci\%C3\%AAncia-e-Consentimento-Hidroxicloroquina-Cloroquina-COVID-19.pdf. Acesso em: 21 jun. 2020.

61 TCLE para uso da hidroxicloroquina ou cloroquina no tratamento da Covid-19. Hospital Cárdio Pulmonar. Disponivel em: http://www.cardiopulmonar.com.br/espacomedico/wp-content/uploads/2020/03/Termode-Ci\%C3\%AAncia-e-Consentimento-Hidroxicloroquina-Cloroquina-COVID-19.pdf. Acesso em: 21 jun. 2020. 
de saúde prestar informações com vista a permitir a autodeterminação da pessoa, que tem o direito a consentir ou a recusar a intervenção proposta" ${ }^{62}$

Deste modo, o TCLE representa um documento em que o paciente e o médico estabelecem normas jurídicas para que o primeiro se sujeite ao tratamento não convencional. Consiste em liberdade dada ao paciente de escolher se submeter ou não, desde que esclarecido sobre eventuais riscos e benefícios do tratamento. É o espaço para que o paciente exerça sua vontade dentro dos limites ditados pelas regras jurídicas, dando vida a essa relação. “Vai além de um documento assinado pelo paciente. Ele deve garantir o exercício da autonomia pelo conhecimento de indicações e alternativas terapêuticas. Por trás da formalidade do TCLE deve haver respeito integral ao enfermo [...]". ${ }^{63}$

Considerando que por esse mecanismo a pessoa passa a atuar e decidir, é fundamental que esteja em condições de dar o consentimento livre e esclarecido - ou consentimento informado. E, quando o participante/paciente estiver em situação de vulnerabilidade - como é o caso do menor - que a prive da integridade psíquica ou das condições de expressar livremente o convencimento, deve prevalecer o melhor interesse do paciente. ${ }^{64}$ Logo, as representações máximas da autonomia em tratamentos ainda não consolidados são o TCLE e o termo de assentimento documento análogo para o menor de idade ou legalmente incapaz. ${ }^{65}$

Oportuno mencionar que, em relação à vacinação por imunizantes contra a Covid-19 autorizados pela Anvisa, mesmo as que contam com autorização emergencial, o Poder Legislativo decidiu dispensar a assinatura do termo de consentimento. Entre os argumentos para a dispensa constam o receio de amedrontar a população e a dificuldade de exercer o controle sobre esses termos de consentimento. 66

62 PEREIRA, André Gonçalo Dias. O consentimento informado em Portugal: breves notas. Revista Eletrônica da Faculdade de Direito de Franca, v. 12, n. 2, dez. 2017. p. 21. Disponível em: http://www.revista. direitofranca.br/index.php/refdf/issue/view/38/showToc. Acesso em: 30 abr. 2021.

63 CASTRO, Fernanda de; QUINTANA, Alberto Manuel; MÜNCHEN, Mikaela Aline Bade. Termo de consentimento livre e esclarecido na assistência à saúde. Revista Bioética, Brasília, v. 28, n. 3, 2020.CASTRO, Fernanda de; QUINTANA, Alberto Manuel; MÜNCHEN, Mikaela Aline Bade. Termo de consentimento livre e esclarecido na assistência à saúde, cit., p. 526.

64 KONDER, Carlos Nelson; TEIXEIRA, Ana Carolina Brochado. Crianças e adolescentes na condição de pacientes médicos: desafios da ponderação entre autonomia e vulnerabilidade. Pensar, Fortaleza, v. 21, n. 1, p. 70-93, jan./abr. 2016. p. 77. Disponível em: https://periodicos.unifor.br/rpen/issue/view/400. Acesso em: 3 maio 2021.

65 CASTRO-SILVA, Igor Luco; MACIEL, Jacques Antonio Cavalcante. Panorama de pesquisas com seres humanos sobre Covid-19 no Brasil. Revista Bioética, Brasília, v. 28, n. 4, p. 655-663, 2020. p. 659. Disponível em: https://revistabioetica.cfm.org.br/index.php/revista_bioetica/issue/view/75. Acesso em: 2 maio 2021.

66 BRANDÃO, Francisco. Câmara dispensa população de assinar termo para ser vacinada. Agência Câmara de Notícias, 18 dez. 2020. Disponível em: https://www.camara.leg.br/noticias/717822-camara-dispensapopulacao-de-assinar-termo-para-ser-vacinada. Acesso: 3 maio 2021. 
Em poucas palavras, na atual crise sanitária, o TCLE revela-se um documento fundamental para as partes, que tem o objetivo inicial de proteger o paciente, assegurar a sua autonomia, mas também de resguardar a responsabilidade do médico e do hospital.

\section{Da responsabilidade civil em experiência terapêutica}

É certo que, até o momento, não há agentes farmacológicos aprovados em todas as fases e isentos de riscos para o tratamento da Covid-19, mas já há relatos de efeitos adversos fatais em pacientes sob o uso de drogas-teste. ${ }^{67}$ Logo, no tocante à responsabilidade civil, é essencial diferenciar se o tratamento do paciente com Covid-19 ocorre no contexto de um estudo científico com seres humanos, sob a chancela da Conep, ou consiste em simples terapêutica em benefício do próprio paciente.

Adverte-se não ser a mesma legislação aplicada às duas situações: para danos decorrentes no ambiente da pesquisa com seres humanos, defende-se $o$ afastamento do Código de Defesa do Consumidor e a incidência do Código Civil. Isso porque as ações médicas experimentais são destituídas de contornos econômicos, não alimentam intenção lucrativa direta e excluem-se do mercado de consumo. 0 paciente não remunera o pesquisador pelo trabalho e o procedimento não está disponibilizado à população em geral. A gratuidade é a regra básica da pesquisa e, em relação aos danos, podem ser responsabilizados pesquisador, instituição e patrocinador.

No tocante à responsabilidade civil médica e hospitalar em tratamentos prestados aos pacientes com a Covid-19, sem que eles sejam inseridos em investigações científicas, o regime legal é semelhante ao dos tratamentos consolidados, apesar das inúmeras particularidades. De início, considera-se que o ambiente extraordinário da pandemia requer maior prudência na exegese, pois, tanto os médicos quanto os demais profissionais da área da saúde estão em situação de pressão e com exposição da própria saúde. Portanto, é justo que a análise de sua atuação não tenha o mesmo rigor de uma conduta médica julgada em condições ditas "normais". ${ }^{68}$

67 CASTRO-SILVA, Igor Luco; MACIEL, Jacques Antonio Cavalcante. Panorama de pesquisas com seres humanos sobre Covid-19 no Brasil. Revista Bioética, Brasília, v. 28, n. 4, p. 655-663, 2020. p. 659. Disponível em: https://revistabioetica.cfm.org.br/index.php/revista_bioetica/issue/view/75. Acesso em: 2 maio 2021.

68 SOARES, Flaviana Rampazzo; DADALTO, Luciana. Responsabilidade médica e prescrição off-label de medicamentos no tratamento da covid-19. Revista Iberc, v. 3, n. 2, p. 1-22, maio/ago. 2020. p. 18. Disponível em: https://revistaiberc.responsabilidadecivil.org/iberc/article/view/112. Acesso em: 3 maio 2021. 
Pondera-se a falta de profissionais da saúde, de leitos e equipamentos, bem como de insumos, situação observada com os anestésicos. Ademais, a Lei № 13.989, de 15.4.2020, autoriza o uso em caráter emergencial da telemedicina, durante a crise causada pelo coronavírus. De acordo com a norma, o atendimento médico se verifica por meio de recursos tecnológicos, restando impossibilitada a realização de exames físicos durante as consultas. "A telemedicina pode ser conceituada, grosso modo, como o exercício da medicina à distância. Para isso, utiliza canais de conexão virtual, basicamente as tecnologias de informação e comunicação veiculadas pela Internet". ${ }^{69}$

Outra providência questionável em período de normalidade, mas admitida durante a atual crise sanitária, é o denominado uso off label, ${ }^{70}$ isto é, a substância é prescrita pelo médico para indicações diversas daquelas constantes na bula, ${ }^{71}$ conforme aqui já mencionado. Apesar de esse uso não encontrar consenso na Anvisa, no CFM e nos tribunais pátrios, quando a vida humana necessita sobreviver à pandemia e cada vida equivale à toda humanidade, "a solução de uso de medicamentos off label para além da prescrição médica torna-se prescrição ética, como uma outra esperança que se renova". ${ }^{72}$

Além do uso off label, observa-se também o denominado uso compassivo, ou seja, emprego de medicamentos experimentais ainda não disponíveis ao uso

69 GARCIA, Lara Rocha; VALENTE, Silvio Eduardo. Telemedicina, telessaúde e e-saúde: conceitos, desafios e oportunidades. In: SCALQUETTE, Ana Cláudia; SCALQUETTE, Rodrigo Arnoni (Coord.). Biotecnologia, biodireito e saúde: novas fronteiras da ciência jurídica. Indaiatuba: Foco, 2019. v. 2. p. 145.

70 No aspecto regulamentar, existem três tipos de prescrição: “a on label, para os casos de a recomendação de utilização do medicamento guardar fielmente as orientações indicadas pelo fabricante e ou importador na bula; b) off label, nas hipóteses em que a droga é empregada para finalidade terapêutica diversa ou em dosagem diferente daquela indicada na bula; c) silente label, quando se tratar de medicamento em relação ao qual a agência regulamentadora ainda não se pronunciou" (SÁ, Maria de Fátima Freire de; FERREIRA, Pedro Henrique Menezes. A prescrição off label de medicamentos: análise do entendimento do Superior Tribunal de Justiça por ocasião dos recursos especiais nํ⒈721.705/SP e no 1.729.566/SP. Revista Brasileira de Direito Civil - RBDCivil, Belo Horizonte, v. 21, p. 147-161, jul./set. 2019. p. 150. Disponível em: https://rbdcivil.ibdcivil.org.br/rbdc/article/view/469. Acesso em: 3 maio 2021).

71 O medicamento, aprovado e registrado para determinada indicação na Agência Nacional de Vigilância Sanitária (Anvisa), muitas vezes é prescrito pelo médico para indicações diversas daquelas constantes na respectiva bula. É o uso off label do medicamento, considerado experimental, podendo estar a nova indicação em fase de estudos ou vir a ser estudada em projetos futuros. Segundo entendimento da Anvisa: "O uso off label de um medicamento é feito por conta e risco do médico que o prescreve e pode eventualmente vir a caracterizar um erro médico, mas em grande parte das vezes trata-se de uso essencialmente correto, apenas ainda não aprovado. Há casos mesmo em que esta indicação nunca será aprovada por uma agência reguladora, como no caso de doenças raras, cujo tratamento medicamentoso só é respaldado por séries de casos. Tais indicações possivelmente nunca constarão da bula do medicamento porque jamais serão estudadas por ensaios clínicos" (BRASIL. Agência Nacional de Vigilância Sanitária. Como a Anvisa vê o uso off label de medicamentos. 2005. Disponível em: http://www.anvisa.gov.br/medicamentos/registro/ registro_offlabel.htm. Acesso em: 3 jun. 2016).

72 ALVES, Jones Figueirêdo Alves. O uso off label de medicamentos em combate da pandemia da Covid-19. Consultor Jurídico, 10 abr. 2020. p. 3. Disponivel em: https://www.conjur.com.br/2020-abr-10/jones-alvesuso-off-label-medicamentos-combate-covid-19. Acesso em: 3 maio 2021. 
generalizado. ${ }^{73} \mathrm{~A}$ reparação de danos nas duas hipóteses não pode ser idêntica àquela existente em período de normalidade e a conduta médica será lícita se praticada de boa-fé, em dosagem adequada, com segurança admissível em contexto atípico e desde que não haja evidência científica comprovando o malefício. ${ }^{74}$

Como a terapêutica aplicada não se encontra reconhecida, a responsabilidade médica é contratual, uma vez que somente será lícita se o profissional obtiver o consentimento do paciente ou do representante legal, precedido de todas as informações essenciais, incluindo-se a característica inovadora e os riscos envolvidos.

No tocante à legislação, aplicam-se aos tratamentos sem comprovação científica - mas excluídos de um protocolo de pesquisa, as regras da responsabilidade civil insculpidas no Código de Defesa do Consumidor e no Código Civil. Portanto, interpreta-se o art. 951 do Código Civil, em consonância com o estatuto consumerista, que regula a responsabilidade dos prestadores de serviços, isto é, serviços médicos, clínicos e hospitalares, realizados individual ou coletivamente. Tal responsabilidade tem sido considerada configuradora de responsabilidade contratual, indicando uma tendência tanto doutrinária quanto jurisprudencial de maior favorecimento das vítimas. ${ }^{75}$

Como ensina Sérgio Cavalieri Filho, a responsabilidade civil decorrente da prestação de serviços direta e pessoal do médico profissional liberal é subjetiva, encontra sede no art. 14, §4ํำ do Código de Defesa do Consumidor e repousa no estatuto da culpa. ${ }^{76}$ Complementa José de Aguiar Dias que a culpa não se presume e à vítima incumbe provar o dano decorrente da negligência, imperícia ou imprudência no exercício da atividade profissional. ${ }^{77}$

Diferentemente, a responsabilidade civil decorrente da prestação de serviços empresariais, incluindo hospitais, clínicas, casas de saúde, laboratórios médicos, é objetiva e regida pelo art. 14, caput, do mesmo diploma. Considera-se também

73 Segundo a Anvisa, o uso compassivo "é caracterizado por ser uma demanda individual. Trata-se da disponibilização de medicamento novo promissor, em desenvolvimento, ainda sem registro na Anvisa, destinado ao uso pessoal de pacientes não participantes de programa de acesso expandido ou de pesquisa clínica" (BRASIL. Agência Nacional de Vigilância Sanitária. Conheça as formas de acesso a medicamentos em estudo. 2018. Disponivel em: http://portal.anvisa.gov.br/noticias/-/asset_publisher/FXrpx9qY7FbU/content/ conheca-as-formas-de-acesso-a-medicamentos-em-fase-de-estudo/219201/pop_up?_101_INSTANCE_ FXrpx9qY7FbU_viewMode=print\&_101_INSTANCE_FXrpx9qY7FbU_languageld=en_US. Acesso em: 23 jun. 2020).

74 SOARES, Flaviana Rampazzo; DADALTO, Luciana. Responsabilidade médica e prescrição off-label de medicamentos no tratamento da covid-19. Revista Iberc, v. 3, n. 2, p. 1-22, maio/ago. 2020. p. 17-18. Disponível em: https://revistaiberc.responsabilidadecivil.org/iberc/article/view/112. Acesso em: 3 maio 2021.

75 TEPEDINO, Gustavo; TERRA, Aline de M. Valverde; GUEDES, Gisela S. da Cruz (Org.). Fundamentos do direito civil: responsabilidade civil. Rio de Janeiro: Forense, 2020. v. 4. p. 190.

76 CAVALIERI FILHO, Sergio. Programa de responsabilidade civil. 12. ed. rev. e ampl. São Paulo: Atlas, 2015. p. 471.

77 DIAS, José de Aguiar. Da responsabilidade civil. 12. ed. revista, atualizada de acordo com o Código Civil de 2002, e aumentada por Rui Berford Dias. Rio de Janeiro: Lumen Juris, 2012. p. 280. 
a responsabilidade objetiva do Estado na prestação de assistência médica, nos termos da Constituição Federal, art. 37, §6ㅇ.

Quanto à responsabilidade objetiva das pessoas jurídicas, destaca-se igualmente uma análise diferenciada no interstício da crise sanitária. A situação excepcional, extraordinária e inevitável (caso fortuito e força maior), afasta a responsabilidade. É o caso do cidadão que vai ao hospital e é contaminado pelo coronavírus. Ainda que consiga provar que a contaminação ocorreu nas dependências do hospital, a responsabilização parece não ser cabível, uma vez que o vírus circula livremente no ar, sendo mais frequente nas imediações de hospitais. ${ }^{78}$

Da mesma forma, quanto ao erro de diagnóstico, o pedido de reparação e de compensação de danos exige maior cautela, já que em época de pandemia faltam testes, e tais equívocos podem se mostrar mais recorrentes. Além do mais, há relativa dificuldade em diferenciar os sintomas da Covid-19 de outras infecções virais.

A prestação de serviços do profissional liberal médico é considerada obrigação de meio, e os médicos não respondem pelo resultado da empreitada, visto que seria ilógico carrear ao profissional a missão de salvamento e recuperação do paciente, ainda mais se consentir em um tratamento sem eficácia comprovada, ciente de todos os riscos, como acontece com a Covid-19. ${ }^{79}$ Apenas em situações específicas, a obrigação será de resultado, como se verifica com o dever de informação e o dever de obter o consentimento livre e esclarecido do paciente ou do seu representante legal. ${ }^{80}$

É conveniente mencionar que tais práticas, por carecerem de comprovações científicas, devem ser utilizadas com cuidado. Os riscos são assumidos pelo enfermo que, após receber as informações e esclarecimentos, consente com a técnica, impulsionado pelas condições de seu estado de saúde. O médico não pode ser responsabilizado por eventos adversos ou pela impossibilidade de cura, se atuou dentro dos parâmetros éticos, científicos e jurídicos, sem excessos e exclusivamente no interesse do paciente.

78 WESENDONCK, Tula. A responsabilidade civil na esfera médica em razão da Covid-19. Migalhas de Responsabilidade Civil. 7 maio 2020. Disponível em: https://www.migalhas.com.br/coluna/migalhas-deresponsabilidade-civil/326237/a-responsabilidade-civil-na-esfera-medica-em-razao-da-covid-19. Acesso: 23 jun. 2020.

$79 \mathrm{Na}$ obrigação de meio, o profissional está incumbido de dedicar atenção, cuidado e diligência, exigidos pelas circunstâncias, de acordo com seu título, com os recursos de que dispõe e com o desenvolvimento atual da ciência. Não garante o resultado. Ao contrário, na denominada obrigação de resultado, o profissional se compromete a realizar determinado fim (AGUIAR JUNIOR, Ruy Rosado de. Responsabilidade civil do médico. Revista dos Tribunais, São Paulo, ano 84, v. 718, p. 33-53, ago. 1995).

80 STOCO, Rui. Tratado de responsabilidade civil: doutrina e jurisprudência. 8. ed. revista, atualizada e ampliada com Comentários ao Código Civil. São Paulo: Revista dos Tribunais, 2011. p. 629. 
Nesse sentido, Tula Wesendonck advoga que, no enfrentamento da Covid-19, a postura profissional pode ser diferente, admitindo-se atitudes mais arriscadas no intuito de salvar o paciente. Diante do risco de morte e do desconhecimento sobre o caminho mais seguro, o médico pode "tomar uma atitude positiva em usar um medicamento não testado adequadamente ao invés de permanecer passivo e preso por standards de conduta que não são exigiveis nas circunstâncias atuais". 81

Por sua vez, se constatada a improvisação excessiva por parte do médico no combate à Covid-19, caracterizada está a imprudência com consequente responsabilidade pelos danos causados. É o que se extrai dos ensinamentos de Fabrício Zamprogna Matielo: 82

[...] improvisar em Medicina é caminho dos mais perigosos e reprováveis se desnecessário. Havendo recursos indicados diretamente para o quadro clínico apresentado, é substancialmente vedado ao facultativo valer-se de inovações cuja eficácia seja discutível, ainda que de comprovada viabilidade para outras situações. Improvisar equivaleria, então, a chamar sobre si todo risco por resultados negativos que viessem a ter lugar, com fundamento na imprudência da conduta adotada. A cada indivíduo incumbe avaliar e delimitar o espaço a partir do qual estará procedendo ao desabrigo da noção comum de sobriedade, e essa observação também cabe a todos aqueles que militam na guarda da integridade alheia, porque nada justifica a opção por atitudes desmedidas causadoras de consequências antijurídicas. Em suma, improvisar ou dar azo a técnicas experimentais equivalem-se como fatores a oportunizar à vítima a busca de indenização ante a superveniência dos danos, quando outras medidas eram exigiveis e indispensáveis à contenção da moléstia. Trata-se de excesso do facultativo no ato de usar das prerrogativas inerentes ao exercício da Medicina, descambando de uma atividade originalmente lídima para a seara das condutas irregulares que reclamam combate enérgico por parte das autoridades constituídas.

Adverte José de Aguiar Dias que o médico não tem o direito de tentar experiências sobre o corpo humano, senão premido pela necessidade de enfrentar 0

81 WESENDONCK, Tula. A responsabilidade civil na esfera médica em razão da Covid-19. Migalhas de Responsabilidade Civil. 7 maio 2020. Disponível em: https://www.migalhas.com.br/coluna/migalhas-deresponsabilidade-civil/326237/a-responsabilidade-civil-na-esfera-medica-em-razao-da-covid-19. Acesso: 23 jun. 2020.

82 MATIELO, Fabrício Zamprogna. Responsabilidade civil do médico. Porto Alegre: Sagra Luzzatto, 1998. p. 117-118. 
mal que ameaça perigosamente o paciente. A sua responsabilidade pelo fato, que constitui abuso ou desvio de poder, não pode ser afastada sob a alegação de que atuou desinteressadamente. Nem o próprio consentimento do interessado teria eficácia nesse sentido. ${ }^{83}$

É condenável, ainda, a submissão à terapêutica experimental sem ou contra a consciente concordância do paciente ou do responsável legalmente autorizado. Atuando dessa maneira, responderá o médico no âmbito penal, ${ }^{84}$ perante o conseIho de ética médica competente, ${ }^{85}$ além de assumir por conta própria a responsabilidade pelos eventuais danos produzidos em razão da intervenção promovida. ${ }^{86}$

A ausência ou a insuficiência de informações e esclarecimentos anteriores à obtenção do consentimento podem comprometer a validade do ato. Rachel Sztajn entende que o menor empenho em informar o paciente ou o familiar enseja presunção de negligência, podendo o profissional responder pelos danos ou pelas promessas que não se realizaram. ${ }^{87}$

A respeito da ausência de consentimento, Fabrício Zamprogna Matielo afirma que somente a superveniência de resultado lesivo poderá resultar em perquirições sobre a culpa do médico, "porque seria esdrúxulo pretender que fosse condenado o profissional que consegue curar o paciente, sob o argumento de que, não obstante, agiu sem o devido consentimento". Para o autor, a "ausência de manifestação favorável do paciente ou de seu responsável apenas funciona como fator a mais na demonstração da culpa pelo resultado danoso, mas nunca como item isolado a viabilizar demandas judiciais". ${ }^{88}$ Tal posicionamento não é pacífico entre os juristas.

83 DIAS, José de Aguiar. Da responsabilidade civil. 12. ed. revista, atualizada de acordo com o Código Civil de 2002, e aumentada por Rui Berford Dias. Rio de Janeiro: Lumen Juris, 2012. p. 290.

84 Constranger o paciente à realização de um tratamento, que foi expressamente recusado, configura o crime de constrangimento ilegal (caput do art. 146 do Código Penal), pois "ninguém será obrigado a fazer ou deixar de fazer alguma coisa senão em virtude de lei” (art. 5ํ, II, da Constituição Federal). A autonomia do paciente é privilegiada (art. 15 do Código Civil). "Não há em nossa legislação dispositivo legal que obrigue um paciente a aceitar ou a submeter-se a um determinado tratamento médico". E, em relação à excludente do art. 146, §3ํ, I, do Código Penal, ela só é aplicada "nas situações em que é impossível descobrir os desejos do paciente" (confira: AZEVEDO, Álvaro Villaça. Autonomia do paciente e direito de escolha de tratamento médico sem transfusão de sangue. In: AZEVEDO, Álvaro Villaça; LIGIERA, Wilson Ricardo (Coord.). Direitos do paciente. São Paulo: Saraiva, 2012. p. 271-302).

85 A Resolução CFM no 1.931/2009, Código de Ética Médica, no art. 22, dispõe que é vedado ao médico “Deixar de obter consentimento do paciente ou de seu representante legal após esclarecê-lo sobre o procedimento a ser realizado, salvo em caso de risco iminente de morte". E o art. 102, parágrafo único, esclarece que "A utilização de terapêutica experimental é permitida quando aceita pelos órgãos competentes e com o consentimento do paciente ou de seu representante legal, adequadamente esclarecidos da situação e das possíveis consequências" (BRASIL. Conselho Federal de Medicina. Resolução n. 1.931/2009. Código de Ética Médica, 2009. Disponível em: http://portal.cfm.org.br/. Acesso em: 26 jun. 2016).

86 MATIELO, Fabrício Zamprogna. Responsabilidade civil do médico. Porto Alegre: Sagra Luzzatto, 1998. p. 107.

87 SZTAJN, Rachel. Reflexões sobre consentimento informado. In: AZEVEDO, Álvaro Villaça; LIGIERA, Wilson Ricardo (Coord.). Direitos do paciente. São Paulo: Saraiva, 2012. p. 187.

88 MATIELO, Fabrício Zamprogna. Responsabilidade civil do médico. Porto Alegre: Sagra Luzzatto, 1998. p. $108-109$ 
Guilherme de Oliveira explica que há lesão da dignidade da pessoa no caso de ela ter sido "objeto" de investigação sem ter prestado o consentimento válido. Na situação, o dano ${ }^{89}$

[...] assume uma plena autonomia quando a investigação correu tecnicamente bem e não deixou prejuízos físicos, nem prejuízos psíquicos, para além do sentimento de instrumentalização ilícita da pessoa em causa. Alguma doutrina e jurisprudência estrangeira tem autonomizado, como dano indenizável, esta lesão do direito à autodeterminação em matéria de saúde, quando se tratar de intervenções médicas de diagnóstico e terapêutica; ora, parece haver maior razão para adoptar uma atitude semelhante no âmbito da investigação clínica. ${ }^{90}$

A despeito de o jurista português tratar da investigação clínica, o mesmo raciocínio pode ser estendido para as experimentações terapêuticas. Observa-se uma tendência em considerar a ausência de consentimento como um dano autônomo, independente dos prejuízos físicos ou psíquicos do paciente porque houve uma exposição ao risco.

A falta de consentimento constitui um desrespeito à autodeterminação e à liberdade individual, bens jurídicos essenciais da pessoa. As fontes de consentimento encontram-se nas normas constitucionais que consagram os princípios fundamentais de proteção da vida, da integridade física, da saúde e da dignidade da pessoa humana. O Código Civil, na mesma linha, reflete a proteção da vida, do corpo, da integridade físico-psíquica. Há, ademais, as disposições no Código de Ética Médica definindo os deveres do profissional.

O médico não poderá iniciar a atividade experimental, ainda que necessária, sem a prestação do consentimento do paciente, validamente esclarecido das particularidades da atuação e das possíveis consequências para a preservação da integridade da vida desse mesmo paciente, os graves riscos e as eventuais sequelas. Jamais poderá forçar o doente a receber um procedimento não comprovado. Aqui, sequer cabe falar em privilégio terapêutico.

Adiante-se que a quantificação da indenização, quando se trata de não obtenção do consentimento do paciente, suscita dificuldades, como alerta Miguel Kfouri Neto. Se o dano não foi causado por má prática médica, apesar da ausência do consentimento, a indenização será menor que aquela estabelecida para a hipótese de dano ocasionado por imperícia, imprudência ou negligência. Na fixação

89 OLIVEIRA, Guilherme de. Temas de direito da medicina. 2. ed. Coimbra: Coimbra, 2005. p. 214.

90 OLIVEIRA, Guilherme de. Temas de direito da medicina. 2. ed. Coimbra: Coimbra, 2005. p. 214. 
da indenização, o juiz considerará a denominada perda da chance de cura ou de sobrevivência. ${ }^{91}$

Ainda quanto ao consentimento, o fato de haver aquiescência não isenta o médico da responsabilização civil ou criminal caso o tratamento redunde em dano ao paciente, imputável ao profissional por culpa comprovada. Embora muito utilizado na defesa médica, o consentimento tem os efeitos limitados à atuação, dentro dos padrões normalmente vigentes na medicina, em nada influindo sobre os prejuízos porventura provocados por imprudência, negligência ou imperícia. ${ }^{92}$

No entanto, caberá ao juiz a análise prudente e criteriosa do caso, para que não haja condenação de um profissional responsável e cauteloso, cuja atuação improvisada foi imposta pela ocasião delicada da pandemia e tão somente em benefício dos interesses desse paciente: salvar a sua vida ou saúde. É certo que a terapia experimental envolve riscos de danos, mas não se desconsidera que tais riscos já se encontravam agravados pelo próprio estado de saúde do paciente. A indenização por equidade pode ser oportuna à hipótese.

Ou seja, a regra do art. 944, do Código Civil, que assevera ser a indenização medida pela extensão do dano, há de ser amenizada. Prevalecendo o desequilíbrio entre a gravidade da culpa do agente e o dano suportado pela vítima, caberá ao juiz promover a redução quantitativa da indenização. "Cumpre assinalar que a diminuição equitativa da indenização somente poderá ser operada se a culpa do agente se traduzir leve ou levíssima e se o dano for grande". ${ }^{93}$

Diante do cenário epidemiológico, existe uma proposta legislativa com objetivo de isenção da responsabilidade civil dos profissionais de saúde por simples negligência em tempos de pandemia:

91 KFOURI NETO, Miguel. Responsabilidade civil do médico. 10. ed. rev., atual. e ampl. São Paulo: Revista dos Tribunais, 2019. p. 278.

92 "O médico tem de obter consentimento do paciente ou do responsável para realizar o tratamento, em especial quando envolva risco mais acentuado. Entretanto, essa dose de perigo não deve ultrapassar os limites do tolerável, que é ditada em cada caso concreto. Se assim não proceder, e culminar por captar a vontade do paciente em estágio avançado da doença visando à aplicação de método de riscos desproporcionais, disso poderá resultar a responsabilização civil do facultativo, principalmente quando a terapia sugerida não estiver consolidada no meio científico como sendo tecnicamente viável. Há, portanto, limites a partir dos quais nem mesmo o consentimento do paciente autoriza o médico a agir, porque ainda que em estado terminal da doença, tem de ser respeitada a obrigação de somente tratar o enfermo de acordo com métodos compativeis e que envolvam em abstrato a possibilidade de benefícios que compensem a assunção de determinados riscos" (MATIELO, Fabrício Zamprogna. Responsabilidade civil do médico. Porto Alegre: Sagra Luzzatto, 1998. p. 108; 112 -113).

93 “Não entendemos sua aplicabilidade em hipóteses de atuação culposa do agente, de natureza leve ou levíssima, e danos de pequena extensão, como também em hipótese de conduta do agente com grave culpa e danos de grande monta" (FUJITA, Jorge Shiguemitsu. Responsabilidade civil: indenização por equidade no Novo Código Civil. In: HIRONAKA, Giselda Maria Fernandes Novaes; FALAVIGNA, Maria Clara Osuna Diaz (Coord.). Ensaios sobre responsabilidade civil na pós-modernidade. Porto Alegre: Magister, 2007. p. 237). 


\section{ISENÇÃO DE RESPONSABILIDADE POR SIMPLES NEGLIGÊNCIA}

Art. X. Dadas as circunstâncias urgentes e dramáticas em que médicos, profissionais de saúde e outros provedores do setor médico precisam prestar serviços, o Estado deve garantir que a partir de 20 de março de 2020 até o final da declaração de emergência esses profissionais não sejam responsabilizados por eventos adversos relacionados ao COVID-19, exceto em casos de grave negligência.

§1으 0 mesmo se aplica a outros profissionais e titulares de cargos públicos que tiveram que tomar decisões rápidas e dificeis diretamente relacionadas à crise da COVID-19.

§2 Essas isenções não se aplicam ao Estado, que permanece responsável de acordo com o regime específico de responsabilidade existente. ${ }^{94}$

Segundo Nelson Rosenvald, “os profissionais de saúde precisam de um escudo de responsabilidade civil para que não se preocupem com pretensões judiciais enquanto lutam para salvar vidas". ${ }^{95}$

Ainda que não vinculado à responsabilidade médica e hospitalar, cumpre registrar que, em termos de danos, a Lei no 14.125, de 10.3.2021, dispõe sobre a responsabilidade civil por possíveis eventos adversos causados pela vacinação contra a Covid-19, que podem tanto incapacitar quanto levar à morte. É notório que os imunizantes aprovados "possuem um risco agregado, decorrente da sua apressada descoberta, aprovação e distribuição", ${ }^{96}$ risco este desconhecido pela comunidade científica.

Como muitos laboratórios condicionam o comércio das substâncias à cláusula de isenção de responsabilidade civil, a lei aprovada prevê a responsabilidade da União, dos estados, do Distrito Federal e dos municípios pelos eventos adversos pós-vacinação, desde que a Anvisa tenha concedido o registro ou a autorização temporária de uso emergencial. Tais entes poderão constituir garantias ou contratar seguro privado, nacional ou internacional, em uma ou mais apólices, para a cobertura dos riscos.

94 Disponivel em: https://www.nelsonrosenvald.info/single-post/2020/05/01/POR-UMA-ISEN\%C3\%87\%C3\%830DE-RESPONSABILIDADE-DOS-PROFISSIONAIS-DE-SA\%C3\%9ADE-POR-SIMPLES-NEGLIG\%C3\%8ANCIA-EMTEMPOS-DE-PANDEMIA. Acesso em: 24 jun. 2020.

95 Disponível em: https://www.nelsonrosenvald.info/single-post/2020/05/01/POR-UMA-ISEN\%C3\%87\%C3\%830DE-RESPONSABILIDADE-DOS-PROFISSIONAIS-DE-SA\%C3\%9ADE-POR-SIMPLES-NEGLIG\%C3\%8ANCIA-EMTEMPOS-DE-PANDEMIA. Acesso em: 24 jun. 2020.

96 MECABÔ, Alex. Lei das Vacinas: entre o inócuo, o questionável e o inconstitucional. Consultor Jurídico, 29 mar. 2021. Disponivel em: https://www.conjur.com.br/2021-mar-29/direito-civil-atual-lei-vacinas-entre-ino cuo-questionavel-inconstitucional. Acesso em: 3 maio 2021. 
Resumidamente, deve-se ter em mente a situação de excepcionalidade criada pelo Covid-19 e que os profissionais de saúde em geral lutam como podem - com falta de pessoal, com falta de equipamento, em situação de esgotamento, com toda falta de recursos -, atuando em nome das vidas humanas e tentando salválas. Por isso, a responsabilidade civil deve ser revisitada para que possa condizer com o contexto atípico, momentâneo, que exige esforços de todos.

\section{Conclusão}

Do estudo realizado, algumas conclusões podem ser extraídas, as quais não se apresentam como posições finais, acabadas, mas, ao contrário, se encontram em processo de construção e reflexão. 0 texto traz à baila a problemática dos tratamentos inovadores em tempos de pandemia da Covid-19. Como não há evidências científicas sobre as terapêuticas utilizadas pelos médicos, as práticas podem ocorrer de duas formas: ou o paciente é inserido em um grupo de pesquisa, sob a chancela da Conep, ou ele é tratado individualmente, em seu próprio benefício.

Os relatos das experiências nazistas durante a Segunda Guerra Mundial, seguidos dos julgamentos do Tribunal de Nuremberg, alertaram o mundo para a necessidade de padrões éticos, científicos e jurídicos nas pesquisas envolvendo seres humanos. Ademais, para assegurar a segurança e eficácia de práticas inovadoras na área da saúde, os documentos internacionais e nacionais impõem testes rígidos, que vão desde a pesquisa em laboratório, com animais, à pesquisa com seres humanos sadios ou enfermos.

No entanto, a atual crise sanitária tem demonstrado a necessidade de flexibilização desses padrões para o uso de novos fármacos, medicamentos, vacinas, testes diagnósticos e terapias. O tratamento não consolidado, sem protocolo de pesquisa, em contaminados pelo coronavírus, passa a ser uma das únicas opções de que o paciente dispõe para ser curado ou sobreviver. Nesse sentido, o art. 37 da Declaração de Helsinque se mostra como norteador ao profissional, de forma a evitar arbitrariedades e responsabilidades.

Portanto, o texto trouxe a licitude dos tratamentos experimentais, embasados em legislação infralegal - resoluções, código de ética médica, provimentos do Conselho Federal de Medicina, entre outros, como também em textos legais - em especial o Código Civil, Constituição Federal. A importância do Código Civil para esses tratamentos experimentais encontra respaldo em princípios gerais (já que o Código tem essa abertura com as cláusulas gerais), nos direitos da personalidade, no negócio jurídico e na responsabilidade civil. 
Nesse cenário, o consentimento livre e esclarecido reforçado ganha relevância e reveste-se de um duplo efeito: consuma a aquiescência do paciente, após ser devidamente esclarecido dos aspectos essenciais da intervenção terapêutica, e evita a responsabilidade civil do médico ou do hospital. Observa-se uma tendência em considerar a ausência de consentimento como um dano autônomo, independente dos prejuízos físicos ou psíquicos, pelo simples fato de existir uma exposição ao risco. Tanto o dever de informar como o de colher o consentimento são obrigações de resultado.

Nas experimentações para tratamento da Covid-19, aplicam-se as regras definidas para as práticas consolidadas, mas observando-se as particularidades do cenário atual. A responsabilidade civil do profissional liberal é subjetiva, nos termos do art. 951, do Código Civil, e do art. 14, §4으, do Código de Defesa do Consumidor. Trata-se de responsabilidade contratual e de meio. A responsabilidade é objetiva quando o prestador de serviços é pessoa jurídica (hospitais, clínicas etc.) ou o responsável é o Estado.

Enfim, no atual contexto, o que se tem são mais dúvidas que certezas. Entretanto, a busca da tentativa rápida de se encontrar a cura para o vírus da Covid-19, que já matou, até o momento atual, mais de quatrocentas mil pessoas no Brasil, justifica as ações realizadas pelo Conep para agilizar a análise dos protocolos envolvendo seres humanos. Espera-se que, em breve, a humanidade possa ter a cura para o problema enfrentado. 